\title{
A PERMANÊNCIA DO MODELO INSTRUMENTAL DO ENSINO EM ADMINISTRAÇÃO
}

\section{Breno de Paula Andrade Cruz, MSc}

\section{Steven Dutt-Ross, MSc}

Deborah Moraes Zouain, DSc

\section{RESUMO}

Este trabalho busca aproximar o conceito de indústria cultural apresentado em Dialética do esclarecimento (Adorno e Horkheimer, 1985) ao ensino de administração no Brasil. Utiliza-se também o conceito de esclarecimento como possibilidade de ir contra a massificação do ensino em administração no país. Para apresentar a presença predominante de uma racionalidade instrumental nos cursos no Brasil, 37 instituições de ensino em administração tiveram suas estruturas curriculares analisadas. Foram construídas três categorias: (a) disciplinas profissionalizantes; (b) raciocínio quantitativo, e, (c) estudos organizacionais. A maioria das escolas se encontra num modelo que foi chamado de instrumental neste artigo. Buscando apresentar uma alternativa diferente daquelas usuais, relata-se um caso do PCDA em que é possível discutir uma forma de construção de uma estrutura curricular interdisciplinar e coerente com as necessidades dos alunos.

Palavras-chave : Ensino de administração. Indústria cultural. Esclarecimento.

\begin{abstract}
This paper approach the concept of cultural industry presented in Dialectic of enlightenment (Adorno and Horkheimer, 1985) to the administration teaching in Brazil. It also uses the concept of enlightenment as a possibility to go against the massification of administration education in the country. The paper present the predominant presence of an instrumental rationality in courses in Brazil, analising 37 institutions of administration education structures had their curriculum. We built three categories: (a) professional disciplines, (b) quantitative reasoning, and (c) organizational studies. Most schools are in the instrumental category classified by this article. Showing an alternative different from those usual, reports the case of PCDA where we can discuss a way of building an interdisciplinary curricular structure and consistent with the needs of students.
\end{abstract}

Keywords: Administration education. Cultural industry. Enlightenment. 


\section{REFLETINDO SOBRE O ENSINO DE ADMINISTRAÇÃO NO BRASIL}

A preocupação com o ensino de administração no Brasil retomou seu espaço no âmbito das discussões acadêmicas recentemente, após ser negligenciada por vários anos nos estudos organizacionais no país. Isso talvez possa ser explicado pela excessiva euforia das análises do pragmatismo e de diversos modelos importados que aterrissaram nas empresas brasileiras no final do século passado e que, consequentemente, influenciaram as discussões acadêmicas da área.

Entretanto, embora alguns autores ao longo dos anos tenham abordado o ensino de administração, é no retorno da área de ensino e pesquisa em administração aos encontros da Anpad e nos encontros da Angrad que se revitaliza a discussão na academia sobre as possibilidades, propostas, metodologias e técnicas que podem ser implementadas ou não no ensino de administração no Brasil. Essa importância se consolida atualmente na prática da discussão científica por meio deste primeiro Encontro de Ensino e Pesquisa em Administração e Contabilidade - EnEPQ.

Duas outras características são essenciais para a revitalização dessa discussão: (a) a regulamentação por parte do Ministério da Educação dos cursos de graduação no Brasil e do Conselho Federal de Administração para este curso, e (b) o aumento vertiginoso do número de cursos de graduação e pós-graduação no Brasil.

Essa proliferação dos cursos no extenso território nacional e as dificuldades ou soluções encontradas por professores fizeram com que a área de ensino de administração voltasse a ser foco de investigação e debate em diferentes fóruns de discussão. Temas como construção de currículos e flexibilização curricular, excesso de pragmatismo no ensino, importação do modelo americano do ensino de gestão, e a necessidade da contextualização do ensino às características do país são temas de grande relevância que têm contribuído para o enriquecimento desta discussão Alguns trabalhos, como os de Fischer $(1984,2001)$, Machadoda-Silva et al (1990), Borba et al (2004), Ruas (2004), Silva et al (2005) e Monteiro et al (2005), discutem transversalmente questões relacionadas tanto à epistemologia quanto à prática do ensino desta ciência no Brasil.

A questão central deste trabalho não é discutir o mercado promissor dos cursos de graduação ou pós-graduação em administração no país ou criticar a ação mercantilista do aumento do número de cursos. 0 principal aspecto discutido neste artigo é a necessidade de atender às necessidades específicas de discentes e docentes, valorizando questões específicas (regionais, culturais ou econômicas) que vão contra a massificação do ensino da ciência administrativa.

0 viés funcionalista (próprio da administração) contribui para que o racionalismo esteja presente também no ensino. A simples reprodução (sem reflexividade) por parte dos docentes de métodos e técnicas pode impedir que o aluno exerça sua reflexão acerca do assunto que está sendo repassado. Ou seja, o docente ensina o "como fazer". Além disso, a não utilização de recursos estéticos ou forma de lecionar do educador pode também prejudicar o processo de aprendizagem.

No contexto da educação superior brasileira, Hilton Japiassú (2006), ao abordar a problemática da educação no Brasil destaca que o grande desafio da educação no século XXI é lidar com a contradição entre problemas cada vez mais globais e a permanência de um saber fragmentado, compartimentalizado ou parcelado. Além disso, o filósofo destaca a necessidade de um movimento dialético do global para o local e vice-versa. 
Neste sentido, percebendo as lacunas existentes na pesquisa e prática do ensino de administração no Brasil, a Anpad - sob a coordenação da professora Tânia Fischer (Universidade Federal da Bahia) - vem trabalhando em conjunto com o CFA e com a Angrad para estimular a inovação e a criatividade entre futuros docentes. O Programa de Capacitação Docente em Administração (PCDA) está em fase experimental e conta com duas universidades e três instituições envolvidas no ensino de pós-graduação no país: UFBA, EBAPE e EAESPFGV, UFRGS e PUC-MG.

É baseado no objetivo geral do PCDA - que visa à reflexão e à ação sobre a prática docente que este trabalho propõe analisar o ensino de administração no Brasil por meio dos conceitos do esclarecimento e indústria cultural. Este trabalho tem relevância para os estudos organizacionais brasileiros pelo fato de: (1) abordar tais conceitos da Teoria Crítica da Escola de Frankfurt; (2) descrever por meio dos dados de 37 instituições o modelo racional presente nos cursos; (3) analisar o ensino de administração numa perspectiva crítica no contexto brasileiro, e, (4) contribuir para que novas questões sejam levantadas.

\section{O ESCLARECIMENTO E A INDÚSTRIA CULTURAL}

Esta parte do trabalho apresenta os conceitos trabalhados por Theodor Adorno e Max Horkheimer em Dialética do esclarecimento. No que diz respeito ao conceito de indústria cultural é necessário que se faça um parêntese. Os autores sempre que se referem ao tema discutem-no na perspectiva da massificação da cultura (acesso de uma população a bens ou obras culturais). Entretanto, seus argumentos e análises são amplos e permitem abordar tal conceito para entender o ensino de administração no Brasil.

Para alguns autores, esclarecimento é sinônimo do Iluminismo. Entretanto, Guido Antonio de Almeida, ao apresentar a nota do tradutor em Dialética do esclarecimento, deixa bem claro a importância de não entender o conceito de esclarecimento como Iluminismo, pois este foi um momento histórico, sendo que o conceito de esclarecimento proposto por Adorno e Horkheimer é um processo de racionalização que prossegue na filosofia e na ciência, não se resumindo apenas ao século XVIII.

O pensar de forma crítica é considerado pela sociedade moderna como uma forma negativa de ver as relações sociais do dominado com o dominante. A idéia central do conceito de Adorno e Horkheimer (1985) é formar este pensamento crítico, sendo o esclarecimento necessário à emancipação do indivíduo. A emancipação acontece quando há liberdade. 0 esclarecimento apenas é consumado quando há a liberdade. Não se pode pensar esclarecimento sem liberdade, eles são inseparáveis.

Ao mesmo tempo que o homem se apropria do conhecimento passando pelo processo de esclarecimento, ele deixa a situação de dominado. De acordo com os autores, a superioridade do homem está no saber:

(...) o esclarecimento tem perseguido sempre o objetivo de livrar os homens do medo e de investi-los na posição de senhores. [...] Sua meta é dissolver os mitos e substituir a imaginação pelo saber. [...] Poder e conhecimento são sinônimos. (Adorno e Horkheimer, 1985, p. 19-20).

Poder é sinônimo de conhecimento. Em uma sociedade em que se valoriza o capital social do indivíduo, este comentário é mais que pertinente e, principalmente, aplicável neste início de século. 0 "esclarecimento é totalitário" (Adorno e Horkheimer, 1995, p.22), pois submete um indivíduo ou grupo de indivíduos a um poder. Quem detém este poder sofre uma alienação 
sobre quem ele está exercendo o poder - há uma abstração: distância do sujeito para o objeto.

Logo, fazendo jus ao título do livro, o esclarecimento que emancipa também oprime. Emancipa à medida que torna o indivíduo ciente de um determinado contexto, dando-lhe condições para refletir sobre determinadas situações. Oprime à medida que este indivíduo (agora emancipado) reconhece que pode usar do seu conhecimento para legitimar o seu poder sobre outro indivíduo que está numa situação igual a dele anteriormente.

Apesar de o esclarecimento ser herdeiro do racionalismo, Adorno e Horkheimer destacam que ele não deve seguir um procedimento matemático. De acordo com os autores, há uma supervalorização do pensamento matemático, sendo que nem sempre os dados mostram todas as relações possíveis, não devendo o pensamento se transformar numa mera tautologia.

A idéia do esclarecimento é de se opor à dominação. Ao apresentarem o conceito de indústria cultural em Dialética do esclarecimento, os autores consideram que a sociedade está num caos cultural. Explicitam que tal fenômeno acontece pelo fato de a cultura contemporânea conferir a tudo um ar de semelhança: "Sob o poder do monopólio, toda cultura de massas é idêntica" (Adorno e Horkheimer, 1985, p.114). A explicação para esse isomorfismo é a desculpa de que no ramo artístico há um desejo por parte do público para que a mesma "receita" seja repetida ou replicada - o que nem sempre é verdade. Utiliza-se desta falsa resposta para tornar o desejo do público uma desculpa objetiva e sem réplica.

Dois conceitos são apresentados pelos autores e devem ser explorados neste trabalho: hierarquia de qualidades e esquematismo da produção. A hierarquia de qualidades pode ser entendida como a necessidade de distinção entre os objetos. Por exemplo, os autores dão exemplos de duas revistas (A e B). Embora o conteúdo das revistas seja o mesmo, há uma necessidade de diferenciá-las, e mostrar que a revista A é melhor que a revista $\mathrm{B}$ - o que importa é a distinção. No conceito de esquematismo, apropriado pelos autores do esquematismo kantiano, as pessoas em seu lazer estão orientadas pela unidade de produção, sendo que o esquematismo passa a ser "o primeiro serviço prestado [pela indústria cultural] ao cliente" (Adorno e Horkheimer, 1985, p.117).

A totalidade da indústria cultural acontece porque suas inovações não passam de uma prototipação da produção em massa. A sociedade está forçada a incorporar as características da indústria cultural, uma vez que se coloca a imitação como algo legítimo/absoluto. Ao exemplificar este fenômeno, os autores comentam a massificação dos filmes. Os filmes são feitos de uma forma que proíbe que o telespectador desenvolva uma capacidade intelectual.

Além disso, os enredos sempre são os mesmos: o galã que fracassa e depois se torna herói, ou a história de amor de dois protagonistas que "vivem felizes para sempre no final do filme".

Para os autores, "os clichês [estão] prontos para serem empregados arbitrariamente aqui e ali e completamente definidos pela finalidade que lhes cabe no esquema" (Adorno e Horkheimer, 1985, p.118).

"A violência da sociedade industrial instalou-se nos homens de uma vez por todas. Os produtos da indústria cultural podem ter a certeza de que até mesmo distraídos vão consumi-los alertamente. [...] cada manifestação da indústria cultural reproduz as pessoas tal como as modelou a indústria em seu todo" (Adorno e Horkheimer, 1985, p.118).

No caso da administração, o viés funcionalista ainda predomina no ensino em toda área. 
Comparativamente, ainda são poucas as contribuições que vão ao encontro da quebra deste viés funcionalista. Formou-se um estilo de ensinar, praticar e discutir a administração nessa perspectiva funcionalista. Adorno e Horkheimer comentam as origens da indústria cultural e as relacionam com os países industriais liberais e conceituam estilo como uma maneira de um indivíduo conforma-se com uma lei (social ou não), o que legitima a dominação.

Em uma sociedade em que há supervalorização dos títulos, do capital social de um indivíduo, há uma busca da fuga do cotidiano. Este cotidiano está relacionado às condições de dominado. Entretanto, Adorno e Horkheimer acreditam que a indústria cultural oferece um paraíso, sendo este paraíso uma volta ao próprio cotidiano. Ao mesmo tempo, ela se interessa pelos indivíduos apenas se estes estiverem na condição de empregado ou de cliente.

\section{A INDUSTRIALIZAÇÃO DO ENSINO EM ADMINISTRAÇÃO}

O comércio do conhecimento, considerado como um posto avançado da economia de mercado, não tem conseguido acompanhar qualitativamente o salto quantitativo no número de matrículas no ensino superior (Portella, 2005).

No que diz respeito à discussão sobre a formação do administrador no Brasil, este debate tem sido revestido de aspectos epistemológicos transversais relevantes para entender a temática. A falta de paradigmas fortes, o excesso do pragmatismo nas e das disciplinas profissionalizantes, a proliferação dos MBAs, as habilitações, as estruturas curriculares ou o projeto político pedagógico dos cursos têm sido temas recorrentes no âmago dos poucos espaços de discussão existentes no final da década de 90.

Neste sentido, buscando trazer para o debate a proliferação dos cursos de administração no país e, principalmente, a questão da racionalidade instrumental no ensino de administração é que se buscou em Theodor Adorno e Max Horkheimer o entendimento dos conceitos de esclarecimento e indústria cultural para discutir esta temática.

De acordo com Barros e Passos (2000), a formação do administrador no Brasil é fundamentalmente instrumental. Nesta perspectiva, a industrialização do ensino de administração pode ser relacionada a quatro características específicas: (1) replicação do modelo instrumental americano de pesquisa e ensino; (2) a lógica de mercado da sociedade contemporânea; (3) formatação dos cursos por órgãos influentes da esfera pública e privada, e, (4) a falta de interdisciplinaridade.

No que diz respeito à replicação de um modelo instrumental americano no ensino e pesquisa em administração, algumas características devem ser destacadas. A primeira delas está relacionada ao "berço" das teorias administrativas: EUA. Fischer (2001) destaca que duas instituições americanas tiveram forte influência nos anos de 1950 e 1960: Michigan State University e Southern Califórnia. Neste processo, o pensamento ortodoxo em administração, que traz em seu esqueleto os princípios instrumentais, se legitimou como único e verdadeiro.

Estas características, em algumas instituições, permaneceram presentes por alguns anos. Barros e Passos (2000, p.166) apresentam os princípios da racionalidade instrumental aplicada ao ensino de administração, e ao transcreverem trecho de uma entrevista com uma aluna de uma instituição de ensino em administração na cidade de Salvador (BA), os autores destacam a fala de uma aluna: "eles vinham [os alunos pobres] com uma base muito ruim, principalmente em matemática. Alguns desses alunos eram até jubilados". Os autores vão além ao destacarem que as matérias quantitativas eram lecionadas por engenheiros como que 
para engenheiros, sem contextualização do problema à área administrativa. Logo, prevalecia a lógica cartesiana presente no curso.

Nessa noção de que seguindo um protocolo de ensino é possível abrir um curso, a segunda variável que pode explicar a industrialização dos cursos no Brasil é a lógica de mercado: sua lucratividade. De acordo com Cruz e Souza (2004), a proliferação dos cursos de administração no Brasil pode ser explicada pelo fato de eles não necessitarem de muito capital de investimento, ao contrário de outros cursos que necessitam, por exemplo, de laboratórios específicos para que o graduando possa desenvolver a teoria junto à prática.

Não só as instituições privadas atendem à lógica de mercado. Marilena Chauí (2003) apresenta a reforma por que a universidade passou para atender às demandas do mercado. Para a autora, o ano de 1964 é o divisor de águas da passagem da universidade pública brasileira como instituição social para organização social.

O terceiro aspecto é a formatação dos cursos por órgãos influentes da esfera pública ou privada. Estes órgãos são basicamente o Ministério da Educação (MEC) e o Conselho Federal de Administração (CFA). A regulação por parte do MEC ocorre por meio das diretrizes do ensino superior que regulam as estruturas curriculares dos cursos de graduação no Brasil e, principalmente, pela antiga avaliação do Provão do MEC e agora pelo Exame Nacional de Avaliação dos Estudantes (Enade). Especificamente no Provão, a nota final do curso era condicionada não apenas à avaliação do aluno, mas também do Projeto Político Pedagógico (PPP) do curso, dos títulos dos docentes e da infra-estrutura da instituição.

No que diz respeito ao PPP do curso, uma avaliação positiva acontecia se a instituição respondesse aos parâmetros pré-estabelecidos por uma comissão técnica do MEC. Para obter uma nota de destaque, as instituições formatavam seus PPPs conforme a necessidade de atendimento das exigências da avaliação, e não de acordo com as necessidades do aluno.

Conforme apresentam Cruz e Silva (2004), ao analisarem o PPP de um curso de administração de uma universidade pública os autores, como participantes críticos do processo de implementação do PPP, destacaram várias lacunas entre o proposto no PPP avaliado pelo MEC e a realidade do ensino. Não existiam informações forjadas, entretanto não caracterizava a realidade do ensino.

A última característica que contribui para explicar a massificação do ensino de administração no Brasil é a falta de interdisciplinaridade. Isso não é um problema específico das ciências administrativas, e sim da ciência contemporânea como um todo. Conforme destaca Japiassú (2006), a interdisciplinaridade acontece quando as fronteiras e os pontos de contato entre ciências diferentes se aproximam ou se interpõem, renunciando ao domínio de uma disciplina pelo saber e sendo contra a manipulação totalitária de uma disciplina ${ }^{1}$.

Industrializar significa atender a um modelo previamente estabelecido. Embora existam diretrizes norteadoras, um curso de administração deve possibilitar um raciocínio sistêmico.

Neste sentido, dadas as características apresentadas anteriormente, o próximo item do trabalho tem como objetivo apresentar as características da massificação dos cursos de administração no Brasil por meio da análise de 37 instituições públicas e privadas.

\footnotetext{
${ }^{1}$ Para os autores a disciplina é uma forma de conhecimento que é organizada e ensinada. Quem a organiza detém o poder.
} 


\section{O MODELO INSTRUMENTAL NOS CURSOS DE ADMINISTRAÇÃO}

Esta parte do trabalho analisa empiricamente o modelo de ensino em administração vigente no Brasil a partir da análise de 37 estruturas curriculares de escolas de administração no país. A escolha destas instituições foi baseada no critério de que estas escolas tivessem programas de pós-graduação associados à Anpad. Assim, em um universo de 65 programas (em 2006), de acordo com a disponibilidade das estruturas curriculares de graduação em administração em seus respectivos websites, participaram deste estudo 37 instituições.

Como não se pretende reproduzir as estruturas curriculares destas escolas neste trabalho, três categorias de análise foram criadas para facilitar a interpretação e redirecionar as disciplinas para uma análise mais genérica.

As Disciplinas Profissionalizantes (DP) são aquelas destinadas à formação profissional do administrador. Aqui foram consideradas todas as disciplinas iniciais ou as que utilizam técnicas e métodos avançados referentes às quatro áreas da administração: marketing, produção, recursos humanos e finanças. Também foram consideradas outras disciplinas de outras áreas de conhecimento, que são aplicadas à administração e que assumem um caráter profissionalizante, como é o caso da contabilidade, do direito e da economia.

Nas disciplinas de Raciocínio Quantitativo (RQ) foram consideradas aquelas que tinham como objetivo desenvolver a capacidade matemática e lógica do aluno ou servir como base para outras disciplinas profissionalizantes que necessitam de conhecimentos avançados em matemática na aplicação de técnicas e métodos. Neste sentido, disciplinas como cálculo, álgebra, estatística, métodos quantitativos e introdução à matemática foram consideradas nesta categoria.

Por fim, nas disciplinas relacionadas aos Estudos Organizacionais (E0) o critério de classificação das disciplinas foi condicionado a uma das seguintes características da disciplina: (i) abordar as relações sociais nas organizações - organização não somente no sentido de empresa, mas também qualquer tipo de organização social; ou, (ii) ser interdisciplinar, ou seja, ser construída com mais de uma temática específica, como, por exemplo, o empreendedorismo. Assim, disciplinas como estratégia, teoria das organizações, teoria geral da administração, análise e construção de projetos, ética, metodologia da pesquisa, sociologia e filosofia foram consideradas nesta categoria.

Os dados apresentados na tabela 1 fazem parte da utilização de uma estatística descritiva neste trabalho. Apesar de não modelar e representar uma realidade, a estatística descritiva permite que as informações não se percam no processo de modelagem estatística. Logo, como este trabalho não tem a pretensão de generalizar suas análises, entende-se que por meio da apresentação destes dados é possível explorar a realidade do ensino de administração no Brasil a partir das categorias criadas neste trabalho para análise. 
Tabela 1: distribuição das disciplinas nos cursos analisados

\begin{tabular}{|c|c|c|c|c|c|c|c|}
\hline Instituição & DP & RQ & EO & Total & $D P$ & RO & $E O$ \\
\hline EAESP & 27 & 5 & 16 & 48 & $56,25 \%$ & $10,42 \%$ & $33,33 \%$ \\
\hline EBAPE & 27 & 16 & 19 & 62 & $43,55 \%$ & $25,81 \%$ & $30,65 \%$ \\
\hline ESAG & 41 & 4 & 18 & 63 & $65,08 \%$ & $6,35 \%$ & $28.57 \%$ \\
\hline ESTACIO & 27 & 4 & 17 & 48 & $56,25 \%$ & $8,33 \%$ & $35,42 \%$ \\
\hline FBV & 23 & 4 & 16 & 43 & $53,49 \%$ & $9,30 \%$ & $37,21 \%$ \\
\hline FECAP & 18 & 8 & 12 & 38 & $47,37 \%$ & $21,05 \%$ & $31,58 \%$ \\
\hline FURB & 23 & 4 & 18 & 45 & $51,11 \%$ & $8,89 \%$ & $40,00 \%$ \\
\hline IBMEC-RJ & 20 & 6 & 16 & 42 & $47,62 \%$ & $14,29 \%$ & $38,10 \%$ \\
\hline IMES & 17 & 4 & 7 & 28 & $60,71 \%$ & $14,29 \%$ & $25.00 \%$ \\
\hline MACKIENZE & 33 & 6 & 20 & 59 & $55,93 \%$ & $10,17 \%$ & $33.90 \%$ \\
\hline PUC-MG & 21 & 6 & 21 & 48 & $43,75 \%$ & $12,50 \%$ & $43,75 \%$ \\
\hline PUC-PR & 20 & 5 & 22 & 47 & $42,55 \%$ & $10,64 \%$ & $46,81 \%$ \\
\hline PUC-RJ & 23 & 7 & 15 & 45 & $51,11 \%$ & $15,56 \%$ & $33,33 \%$ \\
\hline PUC-RS & 22 & 3 & 11 & 36 & $61,11 \%$ & $8,33 \%$ & $30,56 \%$ \\
\hline PUC-SP & 27 & 7 & 15 & $\overline{49}$ & $55,10 \%$ & $14,29 \%$ & $30,61 \%$ \\
\hline UEM & 16 & 4 & 15 & 35 & $45,71 \%$ & $11,43 \%$ & $42.86 \%$ \\
\hline UFBA & 15 & 4 & 8 & 27 & $55,56 \%$ & $14,81 \%$ & $29,63 \%$ \\
\hline UFC & 22 & 7 & 13 & 42 & $52,38 \%$ & $16,67 \%$ & $30,95 \%$ \\
\hline UFES & 21 & 8 & 11 & 40 & $52,50 \%$ & $20,00 \%$ & $27,50 \%$ \\
\hline UFLA & 23 & 6 & 18 & 47 & $48,94 \%$ & $12,77 \%$ & $38,30 \%$ \\
\hline UFMG & 21 & 5 & 16 & 42 & $50,00 \%$ & $11,90 \%$ & $38,10 \%$ \\
\hline UFPB & 24 & 4 & 16 & $\overline{44}$ & $54,55 \%$ & $9,09 \%$ & $36,36 \%$ \\
\hline UFPE & 21 & 2 & 12 & 35 & $60,00 \%$ & $5,71 \%$ & $34.29 \%$ \\
\hline UFPR & 23 & 4 & 18 & 41 & $56,10 \%$ & $9,76 \%$ & $43.90 \%$ \\
\hline UFRGS & 24 & 5 & 12 & 41 & $58,54 \%$ & $12,20 \%$ & $29,27 \%$ \\
\hline UFRJ & 22 & 7 & 11 & 40 & $55,00 \%$ & $17,50 \%$ & $27,50 \%$ \\
\hline UFRN & 36 & 5 & 18 & 59 & $61,02 \%$ & $8,47 \%$ & $30,51 \%$ \\
\hline UFSC & 29 & 5 & 11 & 45 & $64,44 \%$ & $11,11 \%$ & $24,44 \%$ \\
\hline UFU & 35 & 4 & 10 & 49 & $71,43 \%$ & $8,16 \%$ & $20,41 \%$ \\
\hline UFV & 22 & 3 & 5 & 30 & $73,33 \%$ & $10,00 \%$ & $16.67 \%$ \\
\hline UNB & 23 & 4 & 9 & 36 & $63,89 \%$ & $11,11 \%$ & $25.00 \%$ \\
\hline UNIFOR & 19 & 4 & 10 & 33 & $57,58 \%$ & $12,12 \%$ & $30,30 \%$ \\
\hline UNIHORIZONTES & 23 & 3 & 13 & 39 & $58,97 \%$ & $7,69 \%$ & $33,33 \%$ \\
\hline UNIMEP & 21 & 3 & 6 & 30 & $70,00 \%$ & $10,00 \%$ & $20,00 \%$ \\
\hline UNISANTOS & 25 & 4 & 17 & 46 & $54,35 \%$ & $8,70 \%$ & $36,96 \%$ \\
\hline UNISINOS & 21 & 3 & 15 & 39 & $53,85 \%$ & $7,69 \%$ & $38,46 \%$ \\
\hline USP & 19 & 2 & 14 & 35 & $54,29 \%$ & $5,71 \%$ & $40.00 \%$ \\
\hline
\end{tabular}

Fonte: Dados da pesquisa

De acordo com a tabela, os cursos de graduação em administração da ESAG (Escola Superior de Administração e Gerência - SP), UFRN (Universidade Federal do Rio Grande do Norte RN), UFU (Universidade Federal de Uberlândia - MG) e Mackenzie (SP) possuem, em comparação com as outras observações no estudo, muito mais disciplinas profissionalizantes do que as outras escolas. No que diz respeito às disciplinas classificadas como raciocínio quantitativo, percebe-se que sua utilização nas estruturas curriculares é baixa em relação às outras duas categorias. A única escola que foge desta distribuição é a Escola Brasileira de Administração Pública e de Empresas (EBAPE), com uma grande concentração de disciplinas quantitativas.

Por fim, a categoria estudos organizacionais apresenta uma distribuição mediana, uma vez que possui maior percentual que a categoria raciocínio quantitativo, e menor percentual de 
participação na estrutura curricular quando comparada à categoria disciplinas profissionalizantes.

\section{IMPLEMENTANDO O DIFERENTE: O CASO DO PCDA}

"Os arraigados preconceitos positivistas cultivam uma epistemologia da dissociação do saber" (Japiassú, 2006, p.2).

Romper com o tradicional, seja em qualquer contexto, é uma tarefa difícil. Em um campo marcado pelo pragmatismo, pela racionalidade instrumental e que se valorizam os meios para se chegar aos fins, o rompimento de um paradigma forte e difundido é ainda mais difícil. Neste sentido, percebe-se que por motivos diversos há certa aceitação acrítica de um modelo racional de ensino de administração no Brasil.

O Programa de Capacitação Docente em Administração (PCDA) - coordenado pela professora Tânia Fischer, da Universidade Federal da Bahia - tem buscado, ainda em sua fase experimental, refletir junto aos alunos de mestrado e doutorado o atual contexto da educação em administração no país, com o intuito de propor novas práticas de ensino na área que permitam resgatar o objetivo da universidade: desenvolver a capacidade crítica e analítica destes alunos e futuros professores.

Para apresentar na prática a facilidade de discussão e implementação de um currículo padronizado e as dificuldades de um modelo oposto (flexível), utiliza-se aqui a experiência de uma das capacitações realizadas com alunos de mestrado e doutorado em umas das instituições que integram a fase experimental do PCDA.

A atividade em sala de aula com os alunos ocorreu da seguinte maneira: o grupo de alunos foi dividido em dois subgrupos. Como parte da metodologia da capacitação, os alunos antes de iniciarem o curso teriam que ler todo o material da disciplina e construir mapas cognitivos a serem entregues à coordenadora da capacitação. Para esta atividade, dois textos especificamente foram utilizados para análise e posterior debate: (1) Praticando o que ensinamos: inovação na oferta do curso de graduação em administração - gestão para a inovação e liderança da Unisinos ${ }^{2}$ e (2) 0 ensino de administração por um iniciante ${ }^{3}$.

Cada grupo, de aproximadamente 10 pessoas, ficou com a análise de um dos textos para o debate em sala. 0 objetivo era problematizar a dificuldade de refletir a construção de um currículo e sua implementação. Ao final da discussão cada grupo deveria apresentar, com base nos textos, um currículo para ser implementado.

0 texto 1 abordava um modelo de organização de currículos diferente do tradicional, destacando a diferença entre projeto de aprendizagem e projeto de ensino. A proposta do texto era construir um método interacionista (instituição-educando) que permitisse o processo de aprendizagem, tendo sua concepção epistemológica baseada na inovação, diagnóstico das necessidades do aluno e na dialética no processo de ensino. Já o texto 2, apesar de inovar na estrutura curricular e apresentar um modelo diferente de organização de currículos, sendo que seus dois primeiros anos de ensino eram generalistas, suas idéias ainda permaneciam numa perspectiva instrumental de ensino.

\footnotetext{
2 Borba et al (2004).

3 Castro (2006).
} 
Ao final da discussão, um membro de cada grupo foi indicado para fazer a apresentação da estrutura curricular do curso de administração que eles iriam implementar com base nos textos. A exposição das idéias do currículo começou pelo grupo que analisou o texto 2. Com base no modelo que tinha dois anos de formação generalista, o aluno indicado pelo grupo apresentou com certa maestria e detalhes a estrutura curricular que o seu grupo planejou. Já o outro grupo não conseguiu cumprir a tarefa e nem elegeu um representante, sendo que todos os membros discutiram a dificuldade de implementar a estrutura baseada no texto que leram.

A dificuldade principal foi justamente romper com a concepção tradicional de estruturação das disciplinas de modo separado, ou seja, dividir as disciplinas nas áreas de marketing, finanças, produção, recursos humanos. Ao se buscar abordar um problema numa perspectiva transversal, as dificuldades de lidar com o diferente apareceram.

Em uma cultura em que a busca do poder (dominação) é cada vez mais intensa, como propor o diálogo como forma de resolução de problemas em organizações que buscam como fim a máxima rentabilidade? 0 que este tipo de currículo propõe é justamente o pensar crítico, sistêmico e analítico das organizações, lembrando sempre que as organizações são sistemas de relações sociais.

\section{REFLEXÕES FINAIS}

As disciplinas profissionalizantes são necessárias à capacitação do administrador. Os métodos também são importantes no gerenciamento das empresas. Entretanto, eles não são donos da verdade e tampouco resolvem todos os problemas de uma organização. Por mais que a administração seja uma ciência socialmente aplicável, seria necessário (re)pensar a massificação do seu ensino por meio do exagero das disciplinas profissionalizantes? Discutir, analisar e pensar interdisciplinarmente é ainda a função da universidade na formação de um profissional crítico.

O saber interdisciplinar questiona a verdade acabada e os dogmas. 0 "saber" ensinado é um saber alienado e fragmentado, não permitindo uma posição crítica e analítica do educando. 0 novo incomoda, transmite medo e recusa além de impedir a liberdade do pensar, do emancipar (Japiassú, 2006).

Contextualizar deve ser o verbo norteador de uma estrutura curricular construída a partir de uma perspectiva interdisciplinar. A concepção da maior parte dos alunos sobre administração está ligada aos exemplos das multinacionais encontrados nos livros dos grandes "gurus" da administração, adotados na maioria das instituições. Por exemplo, por que não discutir a atuação das micro e pequenas empresas? A organização de arranjos produtivos locais e consórcios de exportação no Brasil? Estes são temas relevantes, muitas vezes próximos à realidade do estudante e que são deixados à margem do ensino de administração por causa da massificação das estruturas, bibliografias ou experiência do docente.

Neste sentido, a massificação dos cursos de administração no Brasil pode ser aproximada do conceito de indústria cultural apresentado por Adorno e Horkheimer. Os motivos da massificação. Ao mesmo tempo, o conceito de esclarecimento como emancipador do indivíduo - livrar o homem da dominação - ajuda a pensar a necessidade de romper com o paradigma racional funcionalista presente no ensino de administração no Brasil. Apesar de o esclarecimento ser meta-teórico para Adorno e Horkheimer, em Habermas, por meio do conceito de racionalidade comunicativa encontra-se uma saída contra a dominação. A busca do diálogo com o ambiente (interno e externo) e com o aluno deve ser construída com o 
objetivo de contextualizar o ensino de administração com as necessidades dos estudantes.

Este estudo contribui ao inovar e buscar na teoria crítica conceitos que podem ajudar na possibilidade de construir de forma coletiva e crítica o arcabouço de um novo paradigma de ensino de administração no Brasil. Ao mesmo tempo, lança insights sobre questões que podem ser pesquisadas por outros pesquisadores como, por exemplo: há predominância das disciplinas profissionalizantes em estados ou regiões do país? Há necessidade de discutir esse excesso de profissionalização no processo de ensino na área? 0 pensar interdisciplinar está efetivamente presente? Há relação entre desempenho no Enade e a distribuição percentual das disciplinas nas categorias desenvolvidas neste estudo? ${ }^{4}$

A concepção epistemológica do curso é extremamente relevante na construção de um profissional com capacidade crítica e analítica. Paradigmas fortes das ciências sociais devem ser considerados na construção da estrutura curricular, uma vez que o administrador está inserido num campo em que predominam as relações sociais entre os diversos atores. A replicação de modelos e métodos deve ser substituída pela inovação e mudança, uma vez que o administrador deve estar apto a lidar com o inusitado e com as peculiaridades de uma sociedade mutável. Assim, são necessários o esclarecimento e a fuga da massificação para que o educando possa refletir e colocar em prática a racionalidade comunicativa.

O objetivo deste trabalho foi aproximar o conceito de indústria cultural ao processo de massificação do ensino de administração no Brasil. Neste sentido, a noção de esclarecimento é relevante a partir do momento em que as constantes mudanças nas relações sociais contribuem para repensar o indivíduo no espaço organizacional. A massificação impede o esclarecimento. 0 administrador contemporâneo deve ter em sua formação ações que despertem e efetivem a interdisciplinaridade. Assim, o ensino de administração deve pautarse, em menor proporção, nas disciplinas profissionalizantes, buscando não somente sua habilidade técnica, mas, principalmente, sua habilidade relacional e sistêmica, evitando a massificação e buscando o esclarecimento.

\section{REFERÊNCIAS}

ADORNO, T. e HORKHEIMER, M. Dialética do esclarecimento - fragmentos filosóficos. Tradução de Guildo Antonio de Almeida. Rio de Janeiro: Jorge Zahar Editor, 1985.

BORBA, G. S. de; SILVEIRA, T. da e FAGGION, G. Praticando o que ensinamos: inovação na oferta do curso de graduação em administração - gestão para a inovação e liderança da Unisinos. In: Encontro da ANPAD, 28., 2004, Curitiba. Anais do XXVIII ENANPAD. Curitiba: ANPAD, 2004. 1 CD-Rom.

BRASIL. Ministério da Educação. Exposição de motivos - anteprojeto de Lei da Educação Superior. Brasília: Ministério da Educação, 2005. (29 jul. 2005). P.29.

CASTRO, C. de M. 0 ensino de administração por um iniciante. Texto para discussão, Rio de Janeiro: EBAPE, 2006.

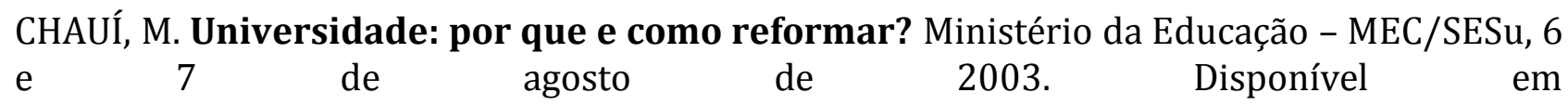

\footnotetext{
${ }^{4}$ No resultado do último Enade, 11 escolas das 37 instituições analisadas neste trabalho (30\%) obtiveram notas máximas na avaliação.
} 
http://www.iq.unesp.br/daws/universidade/arquivos/MarilenaChaui.pdf. Acesso em 19 abr. 2006.

CRUZ, B. de P. A. e SOUZA, I. M. S. Uma reflexão acerca do Projeto Político Pedagógico do curso de administração da Universidade Federal de Lavras. Revista Científica Symposium. Lavras: v.2, n.1, p.73 - 79, 2004.

FISCHER, T. M. D. A difusão do conhecimento sobre organizações e gestão no Brasil: seis propostas de ensino para o decênio 2000/2010. In: Revista de Administração Contemporânea. Associação Nacional de Programas de Pós-Graduação em Administração. Edição Especial (2001). Rio de Janeiro: ANPAD, 2001 - trimestral. (p. 123-139).

Administração pública como área de conhecimento e ensino: a trajetória brasileira. In: Revista de Administração de Empresas. v. 24, n. 4, out./dez. 1984.

HABERMAS, J. Teoria de la acción comunicativa: crítica de la razón funcionalista. Madrid: Taurus, 1987. Vol. 1 e 11.

Instituto Nacional de Estudos e Pesquisas Educacionais Anísio Teixeira (Inep). Censo da educação superior no Brasil em 2003. Disponível em: http://www.inep.gov.br, acesso em 6 ago. 2005.

JAPIASSÚ. H. O espírito interdisciplinar. Cadernos EBAPE.BR. vol. IV, n 3. Disponível em http://www.ebape.fgv.br/cadernosebape/asp/dsp_lst_artigos_edicao.asp?coded=42. Acesso 25 abr 2007.

MACHADO-DA-SILVA, C. L.; CUNHA, V. C. e AMBONI, N. Organizações: o estado da arte da produção acadêmica no Brasil. In: Encontro da ANPAD, 14., 1990, Florianópolis. Anais do XIV ENANPAD. Florianópolis: ANPAD, 1990.

MONTEIRO, P. R. R.; VEIGA, R. T. e FERDINANDUS, B. Abordagens epistemológicas em administração: isolamento, hegemonia ortodoxa ou concepção pluralista? In: Encontro da ANPAD, 29., 2004, Brasília. Anais do XXIX ENANPAD. Brasília: ANPAD, 2005. 1 CDRom.

PORTELLA, E. Educação, comunicação, saber. In: Educação corporativa - desenvolvendo e gerenciando competências. Org. Fátima Bayma. São Paulo: Person Education, 2005.

RUAS, R. L. Literatura, dramatização e ensino em administração - uma experiência de apropriação de práticas teatrais à formação gerencial. In: Encontro da ANPAD, 28., 2004, Curitiba. Anais do XXVIII ENANPAD. Curitiba: ANPAD, 2004. 1 CD-Rom.

SILVA, M. R. da; TEIXEIRA, L. R. e MAGALHÃES, O. A. V. O Ensino de uma "outra gestão": o caso da escola de administração da Universidade Federal da Bahia. In: Encontro da ANPAD, 29., 2004, Brasília. Anais do XXIX ENANPAD. Brasília: ANPAD, 2005. 1 CD-Rom. 